\title{
The influence of the content on structure and properties of geopolymer composites on silicate matrix
}

\author{
Yevgen Lutskin ${ }^{1, *}$, Olena Shynkevych ${ }^{1}$, Igor Myronenko ${ }^{2}$, Stanislav Zakabluk ${ }^{3}$, \\ and Oleksiy Surkov ${ }^{1}$ \\ ${ }^{1}$ Odessa State Academy of Civil Engineering and Architecture, 4 Didrikhson St., 65029, Odessa, \\ Ukraine \\ ${ }^{2}$ Odessa National Maritime University, 34 Mechnikov St., 65029, Odessa, Ukraine \\ ${ }^{3}$ TMM Company, 49a Volodymyrska St., 01001, Kyiv, Ukraine
}

\begin{abstract}
The modern nanotechnology techniques allow receiving advanced composites of silicate matrix of thermal-moisture hardening the low-power technology today. A distinctive feature of geopolymer aerated composites is that their properties according to the basic physical and mechanical parameters exceed of the properties of the silicate matrix. Due to the implementation of a complex activation of highly mobile silicate concrete mixture, that is one of the technological features to obtain this type of composites, energy-saving modes of preparation were provided. The composites and products based on them are characterized by low density at high values of strength, water and crack resistance and heat capacity. The technological features of obtaining effective aerated composites on silica matrix of thermal-moisture hardening set out. The comparative analysis of the influence of the tripoli specific surface to the structuring of silicate matrix properties and porous composites modified of alkali containing additives were carried out. Based on this analysis the mechanism of formation of silicate matrix structure and properties was grounded and proposed. It is shown that the tripoli particles promoted "physical" seal structure of silicate matrix and the formation of capillaries' discontinuous structure, by means of their own micro-porosity.
\end{abstract}

\section{Introduction}

Traditionally the silicate materials are produced by energy-intensive autoclave technology. The basis of this technology is Michaelis W. development by patent № 14195 05.10.1880.

The modern nanotechnology processes allow today to receive progressive composites on the silicate matrix of thermal-moisture hardening according to the low-power technology. Aerated complex activated composites on the silicate matrix are made by casting technology. A distinctive feature of aerated composites is that their properties

* Corresponding author: lutskin@ukr.net 
according to the basic physical and mechanical parameters exceed the properties of the silicate matrix.

At the autoclaves conditions there is activation of crystalline quartz, associated with increased silica solubility. The tendency of minimizing the dissolved lime component in the binder is observed simultaneously. These processes are determined by the peculiarities of chemical thermodynamics of lime and quartz. With higher temperature the solubility of lime decreases, although the rate of dissolution increases and the solubility of crystalline quartz increase [1]. In this case, one of the tasks was to minimize the lime in the composition to reduce the destructive processes. The consequence of these processes was the need to minimize the lime content to its complete binding hydrous calcium to reduce the destructive phenomena.

A large number of research works were devoted to the creation of the desired phase composition of hydrosilicates calcium (GSK). These research works were carried out mainly towards the synthesis of tobermorite, which is formed by minimizing the lime content up to its full bonding. However, the presence of some types of highly basic GSK type hillebrandite, foshagite in the material determines its high frost, air and carbonation resistance under operating conditions [1].

The critical problem of the modern material science is the development and implementation of alternative energy-saving composite binders on nanotechnology and description of the mechanisms of hydration processes at different levels, including nanolevel. The first attempts, to link the mechanical properties of materials with their crystal structure, were made by Griffiths [2].

Many results of works in recent years have shown that for the activated lime-silica composites the presence or absence of any mineral is not exclusive prerequisite for certain physical and mechanical properties [3]. More important factor may be the sizes of the particles of raw mix neoplastic morphology and character of the connection between them. The reactivity mixture, changing of temperature of polymorphic transformations, solubility and kinetics of the displacement in the chemical balance in one direction or another are also connected with the particle size (Le Chatelier). It was found that the properties of ultrafine particles differ in particulate chemical content properties.

The modern nanotechnology receptions allow realizing the effects of the impact of the ultrafine fraction particles. The complex multi-step activation of multicomponent mixtures is used in the research work.

Sufficiently extensive researches of the activation of dispersed particles show the positive effects to the properties of various types of defects, dislocations, etc. It is thermodynamically unstable contacts which can have high strength.

\section{Nanotechnology techniques of producing of the complex activated composites on silicate matrix}

Developed by the authors the complex activation includes the continuous loop of the different types and methods of activation: mechanical, chemical and thermal [4]. Each type of activation is accompanied by effects which create the conditions for the possibility of subsequent type of activation.

The result of the complex activation is the formation of linear defects, dislocations and point positions and substitutions. Furthermore, there may be angle change between the bonds and the appearance of dangling bonds, which leads to the formation of free radicals in the crystals with covalent bonds and the amorphization for molecular crystals.

Each type of activation will be caused by the prevalence of any type of deformations of the solid phase structure. The differences will be responsible for the nature and kind of dislocations with allowance for the extent and duration of external and internal influences. 
Mechanical activation. Mechanical effects in the dispersion medium speed mixer activator provide mechanochemical activation of crystalline quartz surface. The term "mechanochemical reaction" was introduced by W.Ostwald in 1891.

Mechanochemical activation is carried out to the special properties of the newly formed surfaces, especially changing the local chemical and phase content of solids, as well as their aggregate state of under the influence of mechanical effects of high intensity [5].

As nanotechnology reception the mechanochemical activation reduces the viscosity of 3 or more dispersed system containing lime $[4,6]$. This effect of viscosity reducing was used to compensate the increased water demand of the mixture introducing the composite porous opal-cristobalite rocks and using the activation of the binder together with the fine aggregate.

Thermal activation. Using as a binder quick lime promotes the "inner activation" of dispersed system under an elevated temperature $\mathrm{T}=40 \div 60^{\circ} \mathrm{C}$, the formation of multiple point contacts in the dislocation fields are appeared and the conditions for the hydration hardening unrelated in hydrous calcium lime are created.

External thermal activation occurs in conditions of thermal-moisture treatment. In such conditions at $\mathrm{T}=85^{\circ} \mathrm{C}$ contradiction is canceled, which is connected with the increasing the quartz solubility and decreasing lime solubility with increasing its dissolution. In addition, the increase of $\mathrm{pH}$ system causes to create favorable conditions for longevity growths GSK during the operational phase when $11.5 \leq \mathrm{pH} \leq 12.5$.

Chemical activation. According to E. Avvakumov's works [7] with the presence of water in the inorganic solid-phase system "method of soft mechanochemical synthesis" is happened. To obtain composite oxides from the simple oxide hydroxides are used as the starting components one of which is characterized by acidic, the other one is characterized by basic properties. By means of the neutralization reaction the intensification of the processes takes place. In addition, in such system the conditions for the hydrothermal processes are created.

The acid activation occurs by introducing the amorphous-crystalline silica, alkaline activation - the introduction of increased amounts of lime; it raises $\mathrm{pH}$. The replacement of ground quartz sand in the binder by opal-cristobalite rocks enhances to increase frost and water resistance of the silicate matrix while reducing its density matrix to $20-25 \%$.

Moreover, the presence of opal-cristobalite rock in the dispersion causes formation of nanoscale in the GSK pores of these rocks; in this case they are "nanoreactor"; which walls restrict the growth of neoplasm. Also, the presence of particles of porous rocks with different dispersion binder allows adjusting the speed and reaction kinetics of hydration [8].

The use of quick lime determines the possibility of using high modulus liquid glass as one of the alkali addition, so the temperature rise on the forming stage allows regulating rapid setting of such mixture.

Alkali and alkali-containing additives increase the thermodynamic instability of systems by shifting the equilibrium caused by the formation of additional defects on the surface of silica-containing components $[9,10,11]$. Alkali-containing additives are capable to aeration of mixtures under the certain conditions $[12,13,14]$.

In this work, the low-temperature aeration of concrete during introduction of the activation to the mixture for the silicate matrix by liquid glass additives $\mathrm{Na}_{2} \mathrm{O} \cdot \mathrm{nSiO}_{2}+\mathrm{mH}_{2} \mathrm{O}$ and sodium hydroxide $\mathrm{NaOH}$ was provided.

\section{Experiment}

In this study, one of the objectives is to identify local laws of formation of structure and properties of the aerated complex activated composites on the silicate matrix of thermal- 
moisture hardening in order to establish and use in practice the most effective and costeffective methods of nanotechnology in the production process.

To analyze the possibilities of the regulation of the structure and properties of the aerated composites on the silicate matrix six factorial field experiments according to the 24point plan, such as "triangles on the cube" type MTQ was carried out [15]. In the plan three mixed factors and three independent ones of the content vary simultaneously. As three mixed factors the surface area of tripoli as the component of lime-silica binder at levels was fixed: $v_{1}-\mathrm{S}_{\mathrm{sp} 1}=400 \mathrm{~m}^{2} / \mathrm{kg}, \mathrm{v}_{2}-\mathrm{S}_{\mathrm{sp} 2}=500 \mathrm{~m}^{2} / \mathrm{kg}, \mathrm{v}_{3}-\mathrm{S}_{\mathrm{sp} 3}=600 \mathrm{~m}^{2} / \mathrm{kg}$. As three independent factors in the experiments the content of alkali-containing additives were varied: $\mathrm{x}_{4}-$ $\mathrm{NaOH}-(0.5 \div 1) \%, \mathrm{x}_{5}-\mathrm{Na}_{2} \mathrm{O} \cdot n \mathrm{niO}_{2}+\mathrm{mH}_{2} \mathrm{O}-(1 \div 5) \%$ and gypsum additives $\mathrm{x}_{6}-$ $\mathrm{CaSO}_{4} \cdot 2 \mathrm{H}_{2} \mathrm{O}-(2 \div 4) \%$.

According to the experiment results ES model is calculated, which allowed to estimate the effect of alkali-containing additives and the specific surface area of tripoli on the properties and characteristics of the structure of aerated composites on silicate matrix.

The computation experiment has showed that the factor which has the greatest influence to the properties is the specific surface area of tripoli. Due to the synergistic action of alkali additives and liquid glass, taken in optimal ratios for each property and given $\mathrm{S}_{\mathrm{sp}}$ of Tripoli, the aeration of the mixture is achieved, which lowers the density and high values of the properties: compressive strength $R_{b}[M P a]$, bending strength $R_{b t b}[M P a]$, water resistance (coefficient of softening) $\mathrm{k}_{\mathrm{s}}$, crack resistance (critical coefficient of stress intensity) $\mathrm{k}_{\mathrm{Ic}}\left[\mathrm{MPa} \cdot \mathrm{m}^{-0.5}\right]$, heat conductivity (coefficient of heat conductivity) $\lambda[\mathrm{Wt} / \mathrm{m} \cdot \mathrm{K}]$, frost resistance $\mathrm{F}$ [cycles]. The introduction of additives of alkali and liquid glass increases the volume of the mixture to $1.2 \div 1.4$ times. The density of the composite varies from 1300 to $1500 \mathrm{~kg} / \mathrm{m}^{3}$, which is $17 \div 23 \%$ lower than the density of the matrix material and $25 \div 30 \%$ lower than the density of autoclaved silicate brick.

\section{Results and discussion}

According to the experimental results the experimental-statistical (ES) models were calculated. By ES models of optimal values of quality criteria and compositions of mixtures have been installed. Compressive strength $\mathrm{R}_{\mathrm{b}}$ varies from 12 to $18.5 \mathrm{MPa}$, i.e. 1.5 times, and it is in the range of changing of the matrix material strength. Maximum strength is greater than $18 \mathrm{MPa}$, it is obtained for compositions which are contain $5 \%$ of liquid glass, $0.5 \%$ alkali, and $4 \%$ gypsum, $S_{\mathrm{sp}}=400 \mathrm{~m}^{2} / \mathrm{kg}$ of tripoli, the same strength of the silicate matrix is obtained on tripoli with $S_{\mathrm{sp}}=500 \mathrm{~m}^{2} / \mathrm{kg}$.

According to the ES model (1) the coefficient of heat conductivity $\lambda$ of aerated composites under the influence of all six factors varies, 1.9 times, from 0.28 to 0.54 $\mathrm{Wt} / \mathrm{m} \cdot \mathrm{K}$. The minimum value of the theat conductivity coefficient $\lambda=0.28 \mathrm{Wt} / \mathrm{m} \cdot \mathrm{K}$ is obtained on the contents which contain $0.5 \% \mathrm{NaOH}$ and $1 \%$ liquid glass, a mixture of tripoli particles with a specific surface $S_{\mathrm{sp}}=400$ and $\mathrm{S}_{\mathrm{sp}}=600 \mathrm{~m}^{2} / \mathrm{kg}$ in equal ratio and gypsum additive $4 \%$ (Fig. 1a).

Softening coefficient is varied by $\mathrm{k}_{\mathrm{s}} 0.81 \div 1$. The softening factor has another impact of additives. The values $\mathrm{k}_{\mathrm{p}} \geq 0.95$ were obtained with the content $0.75 \% \mathrm{NaOH}$ and $5 \%$ liquid glass on specific surface of tripoli $\mathrm{S}_{\mathrm{sp}}=400 \mathrm{~m}^{2} / \mathrm{kg}$ and the gypsum additive content (Fig. 1b).

Frost resistance of aerated materials is $25-30$ cycles that is lay within the changes frost resistance of matrix material - F25-50. The maximum value of the frost resistance of aerated composites were obtained on $\mathrm{S}_{\mathrm{sp}}=400 \mathrm{~m}^{2} / \mathrm{kg}$, and the content of additives gypsum is $4 \%$. The similar values of frost resistance of silicate matrix were obtained in the mixture of tripoli particles $\mathrm{S}_{\mathrm{sp}}=400$ and $\mathrm{S}_{\mathrm{sp}}=600 \mathrm{~m}^{2} / \mathrm{kg}$ in equal proportions and gypsum content $2.5 \%$. 
a)

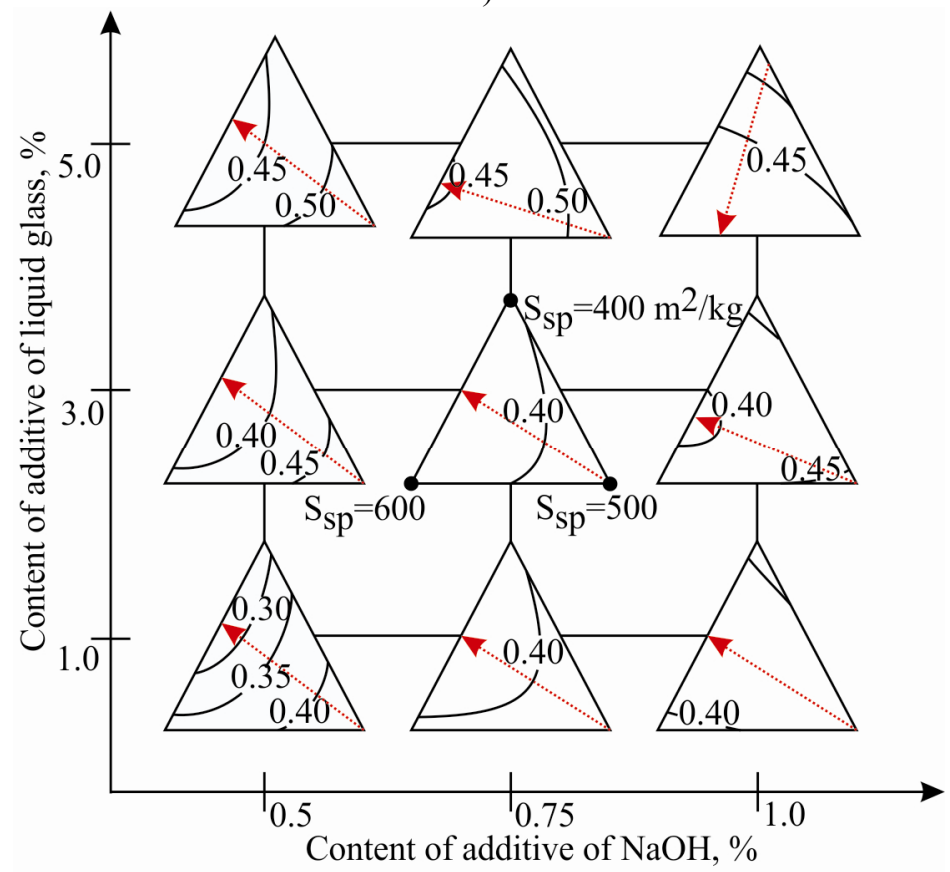

b)

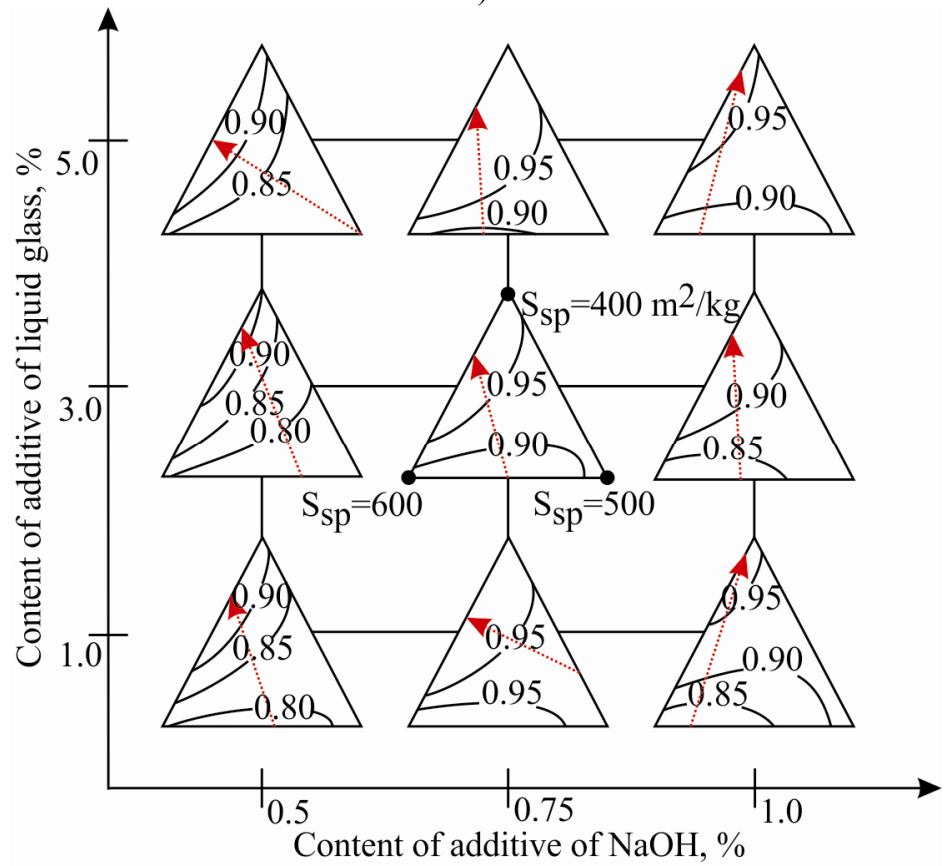

Fig. 1. The influence of additives $\mathrm{NaOH}$ and liquid glass on coefficient of heat conductivity $\lambda$ (a) and softening coefficient $\mathrm{k}_{\mathrm{s}}(\mathrm{b})$ an for a fixed value additive of gypsum. 
The critical coefficient of stress intensity $\mathrm{k}_{\mathrm{Ic}}$ under the influence of all factors varies by 1.8 times, from 0.91 to $1.64 \mathrm{MPa} \cdot \mathrm{m}^{-0.5} . \mathrm{S}_{\mathrm{sp}}$ tripoli acts on $\mathrm{k}_{\mathrm{Ic}}$. According to the ES models, taking into account the quantities of $\mathrm{S}_{\mathrm{sp}}$ tripoli, which provide maximum and minimum values $\mathrm{k}_{\mathrm{Ic}}$, the ratio $\delta \mathrm{k}_{\mathrm{Ic}}=\mathrm{k}_{\mathrm{Ic}}{ }_{\mathrm{max}} / \mathrm{k}_{\mathrm{Ic}}{ }^{\min }=1.1 \div 1.47$ time was calculated.

The maximum values of the critical stress intensity factor $\mathrm{k}_{\mathrm{Ic}}=1.64 \mathrm{MPa} \cdot \mathrm{m}^{-0.5}$ of aerated composites are equal to $\mathrm{k}_{\mathrm{Ic}}$ of matrix material and the minimum value $\mathrm{k}_{\mathrm{Ic}}=0.91 \mathrm{MPa} \cdot \mathrm{m}^{-0.5}$ of aerated composites are twice as $\mathrm{k}_{\mathrm{Ic}}$ of the matrix material. In this case, the maximum and minimum values $\mathrm{k}_{\mathrm{Ic}}$ for porous composite and the matrix material were obtained at the different values of tripoli $\mathrm{S}_{\mathrm{sp}}$. Thus, maximum $\mathrm{k}_{\mathrm{Ic}}$ for aerated composites was obtained on $\mathrm{S}_{\mathrm{sp}}=600 \mathrm{~m}^{2} / \mathrm{kg}$, and for the matrix material - on the mixture $\mathrm{S}_{\mathrm{sp}}=400$ and $\mathrm{S}_{\mathrm{sp}}=600 \mathrm{~m}^{2} / \mathrm{kg}$ with an equal ratio, that may be associated with different particles density in the volume and cramped conditions of aerated.

The visualization of ranges of property changes under the influence alkali-containing additives and the specific surface area of tripoli is shown in Fig. 2.

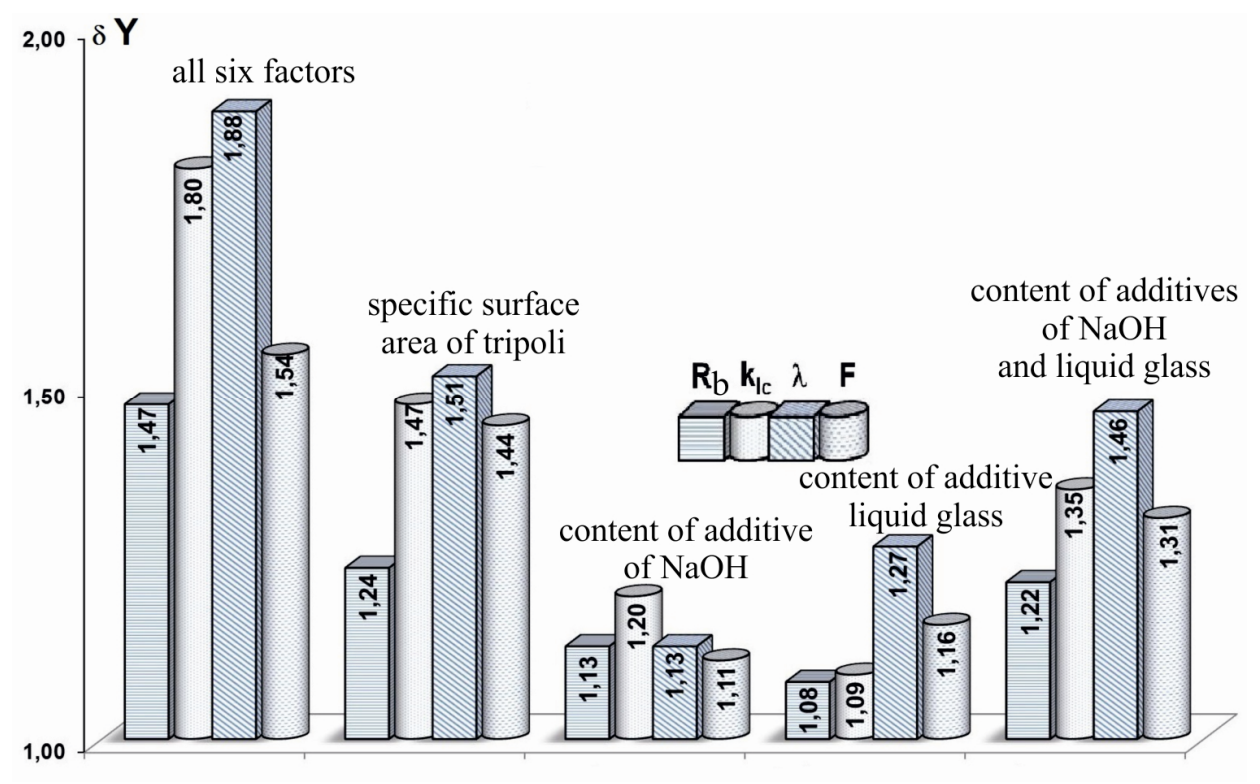

Fig 2. The relative influence of the studied factors and their interactions on the change of properties.

Thus, changed conditions of structure formation by introducing alkali-containing additives promoting aerated, predetermine the introduction of tripoli with a specific surface area, which may be connected, in this case, with the formation of the matrix structure in "straitened circumstances" of interporous partitions. For obtaining optimal compositions of porous composites, introducing alkali-containing additives they condition the necessitate of changes $S_{\text {sp }}$ of tripoli and adjustment of the content of gypsum additives compared with the optimal composition of the silicate matrix at constant quantitative content of other components for the mixture and the conditions of their hardening.

This change of the properties is associated with the change of structural parameters of porous composites under the influence of alkali-containing additives and $\mathrm{S}_{\mathrm{sp}}$ of tripoli. 
a)

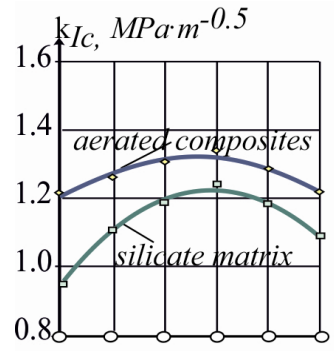

$1, \mathrm{Wt} / \mathrm{m} \cdot \mathrm{K}$
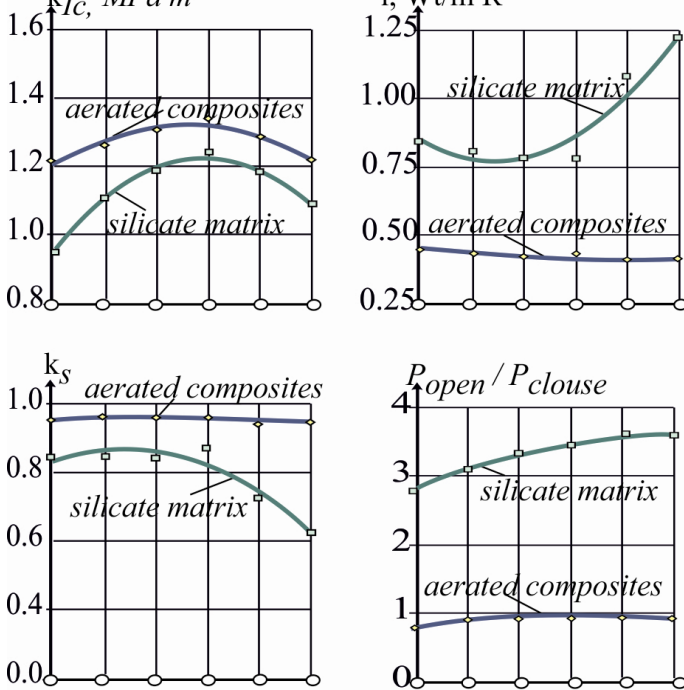

$\mathbf{P}_{\text {total }}=$ const $=\mathbf{4 0 \%}$

b)
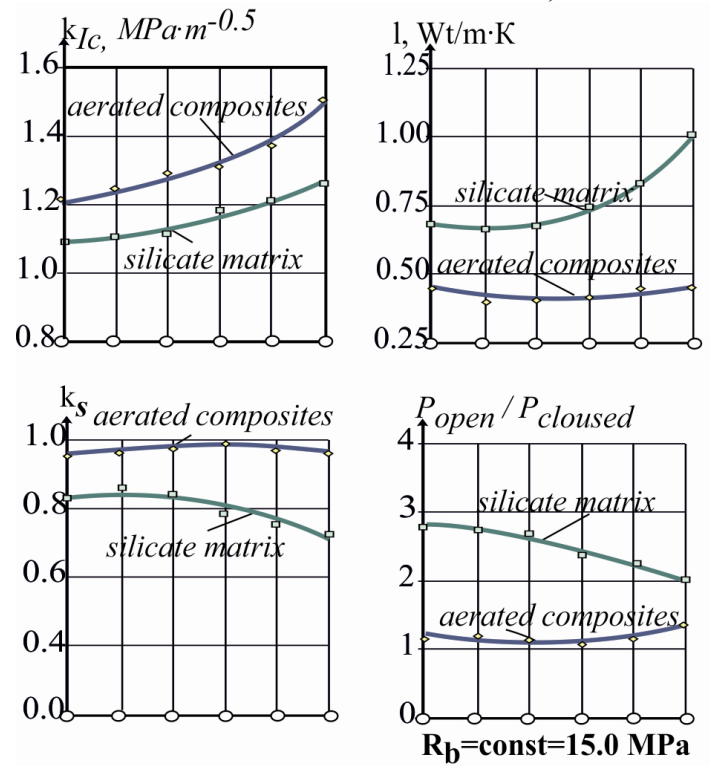
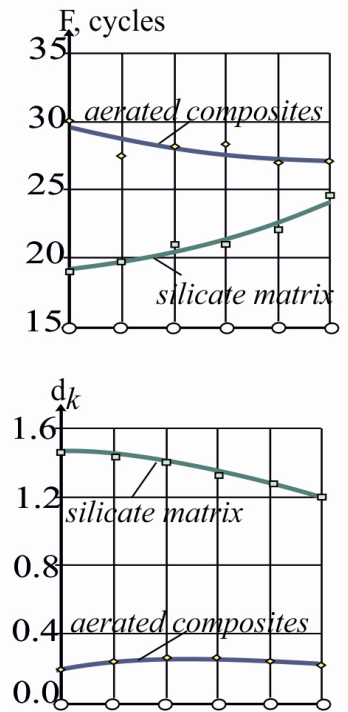

F, cycles
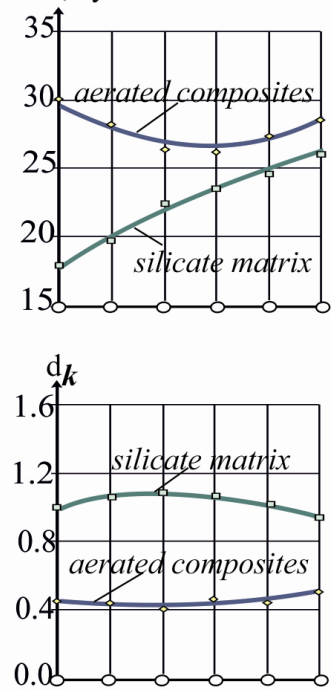

Fig 3. The comparative analysis of the changes in the properties and characteristics of the structure of the silicate matrix and of aerated composites on based it under isoparametric conditions: $\mathrm{P}_{\text {tot }}=$ const $=40 \%$ (a) and $\mathrm{R}_{\mathrm{b}}=$ const $=15.0 \mathrm{MPa}(\mathrm{b})$.

To analyze the impact of the structure characteristics on the properties the ES models of change of total, open and closed porosity and parameters of capillary porosity: $d_{k}$ and $\alpha_{k}$ were calculated. The content of closed pores can be increased by reducing the content of open pores 1.7 times.

The total porosity can be increased to $30 \%$. The average size of the capillaries $d_{k}$ is changed in 4.3 times, the coefficient of distribution uniformity according to their size $\alpha_{k}-$ 


\section{in 2.3 times.}

In the next phase of research using the computational experiments [8] according to ES models, the comparative analysis of property changes and the structure characteristics of the silicate matrix and aerated composites based on the isoparametric conditions at the constant total porosity $\mathrm{P}_{\text {tot }}=$ const $=40 \%$ was carried out.

It was found that at the constant total porosity $\mathrm{P}_{\text {tot }}=$ const $=40 \%$ the aerated composites are characterized by $\mathrm{k}_{\mathrm{Ic}}=1.2 \div 1.35 \mathrm{MPa} \cdot \mathrm{m}^{-0.5}$, that $1.5 \div 1.7$ times higher and the coefficient of heat conductivity is $1.8 \div 2.8$ times lower than at the matrix material, the softening coefficient is $\mathrm{k}_{\mathrm{s}} \geq 0.95$ (Fig.3a).

This improvement is connected with change of the structure parameters. Thus, at the aerated composites comparing with the silicate matrix the ratio of the open and closed pores is reduced 3.5 times, the average size of the capillaries relative $d_{k}$ from 1.2 to 0.35 is reduced more than 3 times.

A similar comparative analysis of property changes and structure characteristics of the silicate matrix and aerated composites based on isoparametric conditions was carried out at $\mathrm{R}_{\mathrm{b}}=$ const $=15.0 \mathrm{MPa}$ (Fig.3b).

Under these conditions, the levels of the properties and their variation intervals vary: $\lambda$ is decreased $1.5 \div 2$ times, $\mathrm{k}_{\mathrm{s}}=1.0, \mathrm{k}_{\mathrm{Ic}}=1.1 \div 1.45 \mathrm{MPa} \cdot \mathrm{m}^{-0.5}$, it confirms the ambiguous influence $\mathrm{P}_{\text {tot }}$ on $\mathrm{R}_{\mathrm{b}} ; \mathrm{R}_{\mathrm{b}}$ is determined not only by the total porosity, but also a variety of other characteristics of the structure.

The optimization problem was to obtain the aerated composites on the silicate matrix, which physic-mechanical properties were above the properties of the silicate matrix.

The isoparametric analysis while retaining $R_{b}=$ const $=15 \mathrm{MPa}$ and $\mathrm{P}_{\text {tot }}=$ const $=40 \%$ showed that the ranges of other properties and structure parameters are significantly reduced: $\delta \lambda=20 \%, \delta \mathrm{R}_{\mathrm{btb}}=18 \%, \delta \mathrm{k}_{\mathrm{s}}=6 \%, \delta \mathrm{k}_{\mathrm{Ic}}=7 \%, \delta \mathrm{P}_{\text {tot }}-10 \%, \delta \alpha_{\mathrm{k}}-5 \%$ with aerated composites simultaneously with two properties of specified level $\left(\mathrm{R}_{\mathrm{b}}\right.$ И $\left.\mathrm{P}_{\text {tot }}\right)$.

Changes of $\delta \lambda, \delta \mathrm{R}_{\mathrm{btb}}, \delta \mathrm{k}_{\mathrm{s}}, \delta \mathrm{k}_{\mathrm{Ic}}$ associated with the presence of a mixture of tripoli different specific surface of tripoli, which confirms its significant influence on the formation of the structure as a silicate matrix and of porous composites based on it.

\section{Conclusion}

The mechanism of formation structure and properties of complex activated lime-silica mixture, modified by the filler in the form of tripoli on quick lime was proposed.

It is shown that the particles of tripoli contribute to seal structure of silicate matrix and the formation of discontinuous structure of capillaries, including its own microporosity. Furthermore, due to the high sorption capacity the tripoli pores can be the matrix from ultrafine size hydrosilicates, which properties differ from the properties of the calcium hydrosilicates formed in the mixture free space. It contributes to obtain the aerated composites with high physical and mechanical properties.

Thus, the structure modification of the silicate matrix by using quicklime, alkalicontaining additives, and tripoli predetermined specific surface area, allows adjusting the levels of the properties and structure parameters of the aerated composites on silicate matrix in a wide range.

According to the results of optimization the contents are recommended which allow to get aerated composites on the silicate matrix given grades of strength, heat conductivity and frost resistance: compressive strength $\mathrm{R}_{\mathrm{b}}-10 \mathrm{MPa}, 12.5 \mathrm{MPa}$, density $\rho=1300 \div 1400 \mathrm{~kg} / \mathrm{m}^{3}$, frost resistance $\mathrm{F} 25$, heat conductivity $\lambda=0.30 \div 0.40 \mathrm{Wt} / \mathrm{m} \cdot \mathrm{K}$, critical coefficient of stress intensity $\mathrm{k}_{\mathrm{Ic}} \geq 1 \mathrm{MPa} \cdot \mathrm{m}^{-0.5}$, coefficient of softening $\mathrm{k}_{\mathrm{s}} \geq 0.9$. 


\section{References}

1. V.I. Babushkin, G.M. Matveev, O.P. Mchedlov-Petrosyan, Thermodynamics of silicates (Moskow, 1986)

2. P.A. Rebinder, N.B. Uriev, Surface phenomena in disperse systems. Physico-chemical mechanics. Selected Works of Rebinder P.A. (Moscow, 1979)

3. E. Shinkevich, E. Lutskin, O. Gnyp, A. Koichev, J. Dotsenko, Proceeding of the 8th Int. Symp. Brittle Matrix Composites 8, 517-525 (2006)

4. O. Shynkevych, Y. Lutskin, O. Koichev, G. Bondarenko, A. Tertychnyi, I. Myronenko, MATEC Web Conf., 116, 01015 (2017)

5. Y.M. Butt, M.M. Sychev, V.V. Timashev, Chemical technology of binders (Moscow, 1980)

6. Y. Lutskin, E. Shinkevich, Proceeding of 14th Int. Congress on the Chemistry of Cement, 2, 632 (2015)

7. E.G. Avvakumov, M. Senna, N. Kosova, W. Soft, Mechanochemical Synthesis a Basis for New Chemical Technologies (Netherlands, Kluwer Academic Publishers, 2001)

8. Y. Lutskin, O. Shynkevych, A. Aniskin, Technical Journal, 11 (4-2017), 60-165 (2017)

9. O. Borziak, S. Vandolovskyi, V. Chajka, V. Perestiuk, O. Romanenko, Matec Web Conf., 116, 01001 (2017)

10. O. Pluhin, A. Plugin, D. Plugin, O. Borziak, O. Dudin, Matec Web of Conf., 116, 01013 (2017)

11. O.I. Demina, A.A. Plugin, E.B. Dedenyova, D.O. Bondarenko, T.A. Kostuk, A.I. Bondarenko, Functional Materials, 24(3), 415-419 (2017)

12. V.D. Gluhovskij, R.F. Runova, S.E. Maksunov, Binders and composite materials of contact hardening (Kiev, 1991)

13. P.V. Kryvenko, E.K. Pushkareva, Durability of slag-alkaline concrete (Kiev, 1993)

14. N.R. Rakhimova, R.Z. Rakhimov, Y.S. Lutskin, V.P. Morozov, Y.N. Osin, Romanian Journal of Materials, 48 (2), 177-184 (2018)

15. V. Voznesenskiy, T. Lyashenko, J. Ivanov, I. Nikolov, Computer and optimization of composite materials (Kiev, 1989) 